\title{
INFECÇÕES DO TRATO URINÁRIO ASSOCIADAS À IDENTIFICAÇÃO DE PATÓGENOS EM GESTANTES VINCULADAS A UNIDADES BÁSICAS DE SAÚDE
}

\author{
URINARY TRACT INFECTIONS ASSOCIATED WITH THE \\ IDENTIFICATION OF PATHOGENS IN PREGNANT WOMEN LINKED \\ TO BASIC HEALTH UNITS
}

\author{
Milena Oliveira da Silva ${ }^{1}$ \\ Dandara Dias Cavalcante Abreu ${ }^{2}$ \\ Alexsandra Laurindo Leite ${ }^{3}$ \\ Vanessa Erika Abrantes Coutinho ${ }^{4}$ \\ Jéssica Alves Moreira ${ }^{5}$
}

RESUMO: Objetivo: Evidenciar as Infecções do Trato Urinário (ITUs) e a identificação dos patógenos em gestantes atendidas na rede pública no município de Cajazeiras, Paraíba, no ano de 2016. Método: Trata-se de uma pesquisa observacional, descritiva e de campo com abordagem quantitativa realizada em três Unidades Básicas de Saúde (UBS) da cidade de Cajazeiras, através da coleta e análise laboratorial de amostras de urina de gestantes que realizam acompanhamento pré-natal. $\mathrm{O}$ trabalho foi executado e dividido em duas etapas: a primeira no laboratório de análises clínicas da Faculdade Santa Maria com a realização do sumário de urina, e a segunda no laboratório de análises clínicas CentralLab com a realização das uroculturas, ambos os estabelecimentos situados na cidade de Cajazeiras. Para a análise estatística, foi utilizado o programa SPSS Statistics versão 23. A pesquisa segue os critérios da resolução 466/12 com aprovação do comitê de ética (parecer 1.706.922). Resultados: A faixa etária do grupo estudado variou de 13 a 33 anos de idade, sendo a maioria adultas jovens. Com relação a renda familiar, a maioria, $40,0 \%$, apresentou renda maior que um salário mínimo. Apenas $46,7 \%$ das gestantes possuíam o $2^{\circ}$ grau completo. Quanto ao estado civil, $63,3 \%$ das mulheres eram casadas. No que tange à etnia, a maior parte das gestantes $(46,7 \%)$ autodeclarou-se parda. Em relação às características clínicas, $74,07 \%$ apresentaram algum sinal ou sintoma de infecção urinária. A

\footnotetext{
${ }^{1}$ Biomédica, formada pela Faculdade Santa Maria - FSM, Cajazeiras - PB.

${ }^{2}$ Biomédica, formada pela Faculdade Santa Maria - FSM, Cajazeiras - PB.

${ }^{3}$ Biomédica, formada Faculdade Leão Sampaio - Unileão - Juazeiro do Norte - CE.

${ }^{4}$ Bióloga, formada pela Universidade Federal da Paraíba - UFPB, João Pessoa - PB.

${ }^{5}$ Biomédica, Faculdade Leão Sampaio - Unileão - Juazeiro do Norte - CE.
} 
maioria das gestantes, $93,33 \%$, realizaram o pré-natal nas datas previstas. As análises microbiológicas das 30 amostras coletadas revelaram a presença do patógeno mais prevalente nas ITUs (Escherichia coli) em uma única amostra. Por fim, no tocante ao tratamento, 40,74\% fizeram uso de algum antibiótico. Conclusão: A infecção urinária denota-se pela existência de patógenos infecciosos e ocupação dos tecidos urinários. Os resultados encontrados no presente estudo (crescimento bacteriano em apenas uma amostra e 5 amostras com crescimento bacteriano inferior a 105 UFC), revelam que, apesar da literatura afirmar a grande prevalência de ITU em gestantes, a pesquisa releva-nos o antagônico, com apenas uma amostra positiva, como também a precariedade dos serviços públicos de saúde ofertados pelas entidades responsáveis.

Palavras chave: Gestantes. Microbiologia. Urina. Unidades Básicas de Saúde.

ABSTRACT: Objective: To highlight Urinary Tract Infections (UTIS) and the identification of pathogens in pregnant women attended in the public network in Cajazeiras, Paraíba, in 2016. Method: This is an observational, descriptive and field research with quantitative approach. This study was carried out at three Basic Health Units $(B H U)$ in the city of Cajazeiras, through the collection and laboratory analysis of urine samples from pregnant women, who are undergoing prenatal care. The work was carried out and divided into two stages, the first in the clinical analysis laboratory of Santa Maria Faculty with the urine summary, and the second stage was produced in the CentralLab clinical analysis laboratory with urine cultures, both establishments located in the city of Cajazeiras. Statistical analysis was performed using the SPSS Statistics version 23 program. The research follows the criteria of resolution 466/12 with the approval of the ethics committee (opinion 1.706.922). Results: The age group of the studied group ranged from 13 to 33 years old, mostly young adults. Regarding family income, most had income greater than one minimum wage $40.0 \%$. Only $46.7 \%$ of pregnant women had completed high school. Regarding marital status, $63.3 \%$ of women were married. Finally, most pregnant women (46.7\%) have ethnicity of brown descent. Regarding clinical characteristics, $74.07 \%$ had some sign or symptom of urinary infection. Microbiological analyzes of the 30 samples collected revealed the presence of the most prevalent pathogen in UTIS (Escherichia coli) in a single sample. Most pregnant women $93.33 \%$ perform prenatal care on the expected dates. With regard to treatment, $40.74 \%$ made use of some antibiotic. Conclusion: Urinary tract infection is denoted by the existence of infectious pathogens and occupation of urinary tissues. The results found in the present study (bacterial growth in only one sample and 5 samples with bacterial growth below 105 UFC), reveal that, despite the literature affirming the high prevalence of UTI in pregnant women, the research reveals the antagonistic, with only a positive sample, as well as the precariousness of public health services offered by the responsible entities.

Keywords: Pregnant women. Microbiology. Urine. Basic Health Units. 


\section{INTRODUÇÃO}

Segundo Alves e seus colaboradores (2016), a infecção urinária denota-se pela proliferação de patógenos infecciosos e ocupação de qualquer parte do trato urinário (uretra, bexiga, ureteres e rins), podendo ser classificada segundo seu posicionamento. As Infecções do Trato Urinário (ITUs) dividem-se em dois distintos grupos: as que comprometem o trato urinário baixo, evidenciadas por meio do diagnóstico de Cistite, podendo apresentar sintomas como disúria, nictúria e dores supra púbicas; e as infecções de trato urinário superior, caracterizadas por Pielonefrite, que se inicia com quadro de cistite acompanhada por febre alta e dores lombares, seguidas por um quadro de processo inflamatório característico (GOMES et al., 2017).

As ITUs são recorrentes na maioria das mulheres devido à anatomia do canal urinário feminino, que é reduzido e localizado próximo ao ânus. A região genital possui facilidade de proliferação de bactérias e entre os fatores que facilitam a manifestação das ITUs destacam-se o uso de roupas muito apertadas, a falta de higienização e as relações sexuais. Durante a gestação, essas infecções estão intimamente ligadas aos índices relevantes de morbimortalidade materna e perinatal (SANTOS; DAMASCENO; SOUTO, 2019).

As ITUs podem ser sintomáticas ou assintomáticas e apresentam-se como uma das patologias mais recorrentes durante à gravidez. As mudanças hormonais e fisiológicas decorrentes da gestação proporcionam acréscimos de infecções urinárias sintomáticas, todavia, as medidas de prevenção das infecções urinárias em gestantes tornam-se reduzidas, uma vez que, neste período, o sistema imunológico da paciente encontra-se imunossuprimido, além de haver uma redução das possibilidades de tratamento devido à toxicidade dos antimicrobianos para o feto (PAULA et al., 2015).

Nesse viés, no decorrer do período de gestação acontece uma atenuação nos rins referente ao acúmulo de urina, o que reduz a ação antibacteriana. Além disso, 
há variações do $\mathrm{pH}$, propiciando a proliferação bacteriana, sobretudo a espécie Escherichia coli, que consiste em um dos principais patógenos causadores das ITUs (FERNANDES, 2015).

Junto a Escherichia coli existem outros patógenos que se fazem vigentes nas ITUs, como Staphylococcus saprophyticus, que representam de $10 \%$ a $20 \%$ dos casos, Staphylococcus aureus, Streptococcus do grupo B e D, Enterococcus faecalis, Klebsiella pneumoniae, Enterobacter sp., Proteus sp., e Pseudomonas sp., dentre outras espécies e gêneros (LACERDA et al., 2015).

Segundo Korb (2013), o fator de virulência dos patógenos, a persistência do vetor, a eficácia da intervenção clínica e o antimicrobiano escolhido para o tratamento são elementos concernentes com o progresso clínico das infecções do trato urinário. A alta incidência das ITUs em gestantes e a variabilidade de patógenos isolados constatam a relevância do diagnóstico laboratorial e clínico durante o pré-natal, pois podem ser inúmeros os prejuízos acarretados tanto para mãe quanto para o feto, quando não há o tratamento efetivo das infecções urinárias.

A ITU se estabelece muito frequentemente durante a gestação e pode ser diagnosticada por um exame de urina em qualquer trimestre durante o pré-natal. Por esse motivo, a atenção, o cuidado e o acompanhamento para com as gestantes durante as suas visitas as Unidades Básicas de Saúde se fazem imprescindíveis, para o correto e rápido diagnostico, garantindo ainda a adesão das mesmas ao tratamento e evitando-se complicações futuras durante a gestação e o parto (VERAS, et al., 2016).

Assim, o presente estudo objetivou investigar a presença de infecção urinária em gestantes da cidade de Cajazeiras - PB cadastradas nas principais Unidades Básicas de Saúde, a partir de amostras de urina, correlacionando com o perfil de sensibilidade aos antimicrobianos, com base em referências bibliográficas.

\section{MATERIAIS E MÉTODOS}


Trata-se de uma pesquisa fundamentada na Resolução 466/2012 do Conselho Nacional de Saúde, sendo de cunho observacional, descritiva e de campo com abordagem quantitativa, realizada em três Unidades Básicas de Saúde (UBS) da cidade de Cajazeiras, no estado da Paraíba, aprovada pelo Comitê de Ética em Pesquisa da Faculdade Santa Maria (parecer 1.706.922, e seguiu todos os critérios para realização de pesquisas com seres humanos. As voluntárias que aceitaram participar da pesquisa assinaram o Termo de Consentimento Livre e Esclarecido (TCLE).

O estudo foi executado e dividido em duas etapas, a primeira no laboratório de análises clínicas da Faculdade Santa Maria com a realização do sumário de urina, e a segunda no laboratório de análises clínicas CentralLab com a realização das uroculturas. Os dois estabelecimentos supracitados estão situados na cidade de Cajazeiras.

Foram coletadas 30 amostras, as quais foram cedidas pelas gestantes em coletores estéreis previamente disponibilizados pelas pesquisadoras. Posteriormente, as amostras foram acondicionadas em caixa térmica, onde permaneceram por 30 minutos, enquanto eram transferidas para o laboratório de análises clínicas da Faculdade Santa Maria para a realização das análises laboratoriais.

A primeira etapa correspondeu ao exame físico, que avaliou, no próprio coletor, a cor, odor, aspecto, volume e depósito das amostras de urina; em seguida, a amostra foi homogeneizada e $10 \mathrm{ml}$ foram transferidas para um tubo cônico onde aconteceu a passagem de uma fita na urina de $5 \mathrm{~mm}$, iniciando assim a segunda etapa do exame de urina, chamada de etapa química. A fita utilizada foi a Uri-Color Check, fabricada pela Wama Diagnóstica, que consegue realizar a determinação semiquantitativa de 10 parâmetros na urina de forma simultânea. De maneira rápida e simplificada, a fita de urina fornece importantes informações acerca de patologias do trato renal.

A etapa química do teste é capaz de identificar a presença ou ausência de substâncias como glicose, proteínas, bilirrubina, urobilinogênio, leucócitos, hemoglobina, nitrito, corpos cetônicos e pH. Após o mergulho das fitas em cada tubo cônico, foram lidas 
através de comparação das cores obtidas com a tabela de leitura fornecida pelo próprio fabricante, e cada resultado foi anotado para posterior tabulação.

Por fim, os tubos cônicos foram centrifugados em centrífuga de bancada para laboratório modelo 80-2B da marca Anabely, com capacidade de acomodar até 12 tubos de $15 \mathrm{ml}$ cada para uso clínico e rotina laboratorial, a uma velocidade de 1500 rpm (ou 302 RCF -Força centrífuga relativa ou força $G$ ) por 5 minutos, que separou o sobrenadante e o precipitado. O sobrenadante foi desprezado no expurgo, e o precipitado foi homogeneizado e pipetado em lâminas de vidro com pipetas de 20 $\mu \mathrm{L}$, posteriormente recobertas por lamínulas medindo $24 \times 32 \mathrm{~mm}$. Realizou-se a sedimentoscopia da urina em microscópio biológico binocular Digilab, em luz baixa, na objetiva de 40x de aumento, sendo visualizadas células epiteliais, leucócitos, hemácias, muco, bactérias, cristais, cilindros e hemácias.

Após a realização dos sumários de urina, as amostras restantes nos coletores foram direcionadas ao laboratório de análises clínicas CentralLab para realização do procedimento de urocultura. Foram realizadas as uroculturas com a semeadura da amostra em placa de cultura em meio Ágar Mackonkey e Muller Hinton. Durante o período de 24 horas, houve o crescimento de colônias, não sendo necessário estender o tempo de incubação pelo período de 48 a 72 horas. Por conseguinte, não foram realizadas as 3 leituras no intervalo de 24 horas, cada uma, para a confirmação da amostra ser positiva para ITU.

É considerada uma ITU, a placa que apresentar contagem bacteriana superior a 100.000 (105) unidades formadoras de colônia (UFC), uma vez que o diagnóstico dessa infecção tem como base a contagem de colônias no exame microbiológico. Sendo assim, foram consideradas positivas as culturas que apresentaram crescimento igual ou superior a 105 UFC/mL. Não houve contaminação dos meios de cultura, estes, então, não apresentaram contagem bacteriana significativa, devendo estar inferior a 105 UFC. Nos casos de crescimento de colônias, essas foram quantificadas e identificadas com o microrganismo causador da infecção, através da realização da técnica de Coloração de Gram podendo ser verificado a presença de microrganismos Gram-positivos ou Gram-negativos.

Também houve a execução das provas bioquímicas para identificação da espécie do microrganismo de acordo com a colônia formada, como as provas da 
catalase, objetivando averiguar a presença da enzima catalase que decompõe o peróxido de hidrogênio em água e oxigênio, presente na cultura, causando a formação de bolhas gasosas quando positivo para catalase e a ausência das bolhas quando negativo. Além desta, foi realizada a prova da coagulase, que verificou a capacidade de reação da enzima na formação de coágulo, capaz de converter fibrinogênio em fibrina, sendo positivo na presença do coágulo e negativo na ausência.

Após a obtenção dos resultados, foram feitos os laudos e entregues às pacientes, as quais foram orientadas a procurar o médico responsável pelo acompanhamento da gestação. Todos os dados coletados nos exames de urina (EAS e urocultura) foram tabulados e analisados estatisticamente, através do programa SPSS Statistics versão 23.

\section{RESULTADOS E DISCUSSÕES}

Atualmente, a infecção urinária tem sido alvo de diversos estudos devido a sua relevância na prudência para com o tratamento à base de antibióticos, uma vez que a maioria dessas substâncias pode provocar grandes complicações para o feto. As ITUs possuem, pois, potencial de acarretar prejuízos, quando não tratada de forma correta, durante a gestação e/ou após o parto, tanto para a mãe, quanto para o feto.

Realizou-se sumário de urina e urocultura, com obtenção de crescimento bacteriano em apenas uma amostra (3,33\%). Essa prevalência de ITU concorda com um estudo que avaliou a prevalência e perfil de susceptibilidade a antimicrobianos de uropatógenos no Instituto Lauro de Souza Lima em Bauru/SP, que obteve uma positividade de apenas $24,2 \%$ (das 605 uroculturas realizadas) apresentaram resultados positivos para ITU (FREITAS, et al., 2016). Ainda, discorda do resultado descrito por Pagnonceli et al. (2010), em um estudo realizado no município de Marechal Cândido Rondon - PR com uma amostra de 34 gestantes e com a obtenção da descrição de $56 \%$ de positividade referente às uroculturas. 
O presente resultado revela, com o resultado encontrado de crescimento bacteriano em uma amostra das trinta analisadas, que podem ter acontecido interferentes desde a coleta inadequada das amostras até o seu acondicionamento e transporte (em condições inapropriadas ou por tempo prolongado) por parte das gestantes, o que pode ter gerado resultados falsos negativos que não foram contabilizados.

Segundo o Ministério da Saúde, em 2012, as ITUs ocorreram em 17\% a 20\% das gestantes, esse fator é devido a inúmeras alterações fisiológicas que ocorrem no corpo da gestante durante o período gestacional e, nesse sentido, no tocante ao trato urinário, essas alterações não são diferentes. O crânio do feto possui a capacidade de deslocar os rins, que sofrem também alterações em seu tamanho, devido ao aumento da vascularização e do líquido intercelular (líquido localizado entre as células corpóreas). Durante a sétima semana de gestação, há uma expansão considerável do trato urinário superior, aumentando a estase urinária e favorecendo o aumento do quadro de infecções durante o período gravídico (KORKES et al., 2014).

O quadro 1 revela os resultados encontrados com relação ao perfil socioeconômico. A idade das gestantes participantes variou entre 13 e 33 anos, classificando-se a maioria como adultas jovens, sendo condizente com a literatura apresentada por Santos e seus colaboradores (2018) que consideram a idade como um dos fatores de maior relevância para o desenvolvimento das ITUs durante a gestação, como mostra seu estudo realizado com gestantes atendidas em Unidades Básicas de Saúde de Cascavel, Paraná, no ano de 2015, que apresentou como resultado que em relação às gestantes acometidas por ITU (125) verificou-se que 61 $(48,80 \%)$ estavam na faixa etária dos 21 aos 30 anos.

Com relação a renda familiar, a maioria apresentou renda maior que um salário mínimo (40,0\%). Apenas $46,7 \%$ das gestantes apresentaram $2^{\circ}$ grau completo. Quanto ao estado civil, 63,3\% das mulheres eram casadas. Por fim, a maior parte das gestantes $(46,7 \%)$ apresentam etnia de descendência parda, sendo concordante com o estudo de Onoh e colaboradores (2013). Nesse estudo, realizado na Nigéria (Federal Medical Center e Hospital de ensino da Universidade de estado Ebonyi), a maioria das gestantes, de uma amostra de 542, também eram 
casadas, correspondendo a uma porcentagem de $97,6 \%$; já os resultados em relação as condições financeiras são discrepantes, pois, em seu estudo, uma maioria de $29,8 \%$ possuem condições financeiras promissoras. Isso é contrário aos resultados apresentados na tabela 1.

O desfavorecimento econômico encontra-se relacionado ao alto reconhecimento dos serviços prestados pelas esferas de saúde. A baixa escolaridade, higienização inadequada e condições inconstantes de moradia são fatores que auxiliam e instigam um possível favorecimento ao progresso das ITUs (MATA et al., 2014). Quanto aos resultados do estudo de Mata e colaboradores (2014), realizado em Maceió, com um total de 80 gestantes, apresentaram renda familiar de 1 a 3 salários mínimos (33,75\%); quanto à cor, $52,50 \%$ das gestantes declararam ser parda, sendo condizente com os dados apresentados no quadro 1. 
Quadro 1 - Renda familiar, grau de escolaridade, estado civil e etnia das gestantes da cidade de Cajazeiras - PB.

\begin{tabular}{|c|c|c|c|c|}
\hline \multicolumn{5}{|c|}{ RENDA FAMILIAR } \\
\hline & FREQUÊNCIA & PORCENTAGEM & $\begin{array}{l}\text { PORCENTAGEM } \\
\text { VÁLIDA }\end{array}$ & $\begin{array}{c}\text { PORCENTAGEM } \\
\text { CUMULATIVA }\end{array}$ \\
\hline Nenhuma & 1 & 3,3 & 3,3 & 3,3 \\
\hline <1 salário & 7 & 23,3 & 23,3 & 26,7 \\
\hline Até 1 salário & 10 & 33,3 & 33,3 & 60,0 \\
\hline >1 salário & 12 & 40,0 & 40,0 & 100,0 \\
\hline Total & 30 & 100,0 & 100,0 & \\
\hline \multicolumn{5}{|c|}{ ESCOLARIDADE } \\
\hline E. F.I & 7 & 23,3 & 23,3 & 23,3 \\
\hline E. F. C. & 3 & 10,0 & 10,0 & 33,3 \\
\hline $2^{\circ}$ incompleto & 2 & 6,7 & 6,7 & 40,0 \\
\hline $2^{\circ}$ completo & 14 & 46,7 & 46,7 & 86,7 \\
\hline $\begin{array}{l}\text { Ensino } \\
\text { superior } \\
\text { completo }\end{array}$ & 4 & 13,3 & 13,3 & 100,0 \\
\hline Total & 30 & 100,0 & 100,0 & \\
\hline \multicolumn{5}{|c|}{ ESTADO CIVIL } \\
\hline Solteira & 10 & 33,3 & 34,5 & 34,5 \\
\hline Casada & 19 & 63,3 & 65,5 & 100 \\
\hline Total & 29 & 96,7 & 100,0 & \\
\hline Omisso & 1 & 3,3 & & \\
\hline \multicolumn{5}{|c|}{ ETNIA } \\
\hline Branca & 2 & 6,7 & 6,7 & 6,7 \\
\hline Parda & 14 & 46,7 & 46,7 & 53,3 \\
\hline Morena & 10 & 33,3 & 33,3 & 86,7 \\
\hline Negra & 4 & 13,3 & 13,3 & 100,0 \\
\hline Total & 30 & 100,0 & 100,0 & \\
\hline
\end{tabular}

Fonte: Autoras, 2016.

Em relação a prevalência de infecções urinárias relacionadas com a trimestralidade da gravidez, os resultados obtidos nesse estudo mostraram que apenas 3,33\% das gestantes positivaram para infecção urinária, sendo que esta ocorreu no primeiro trimestre da gravidez. Esse fator vai de encontro com a literatura e pode ser exemplificado no gráfico 1. 
Gráfico 1: Prevalência de infecção urinária em gestantes de acordo com o trimestre gestacional na cidade de Cajazeiras - PB.

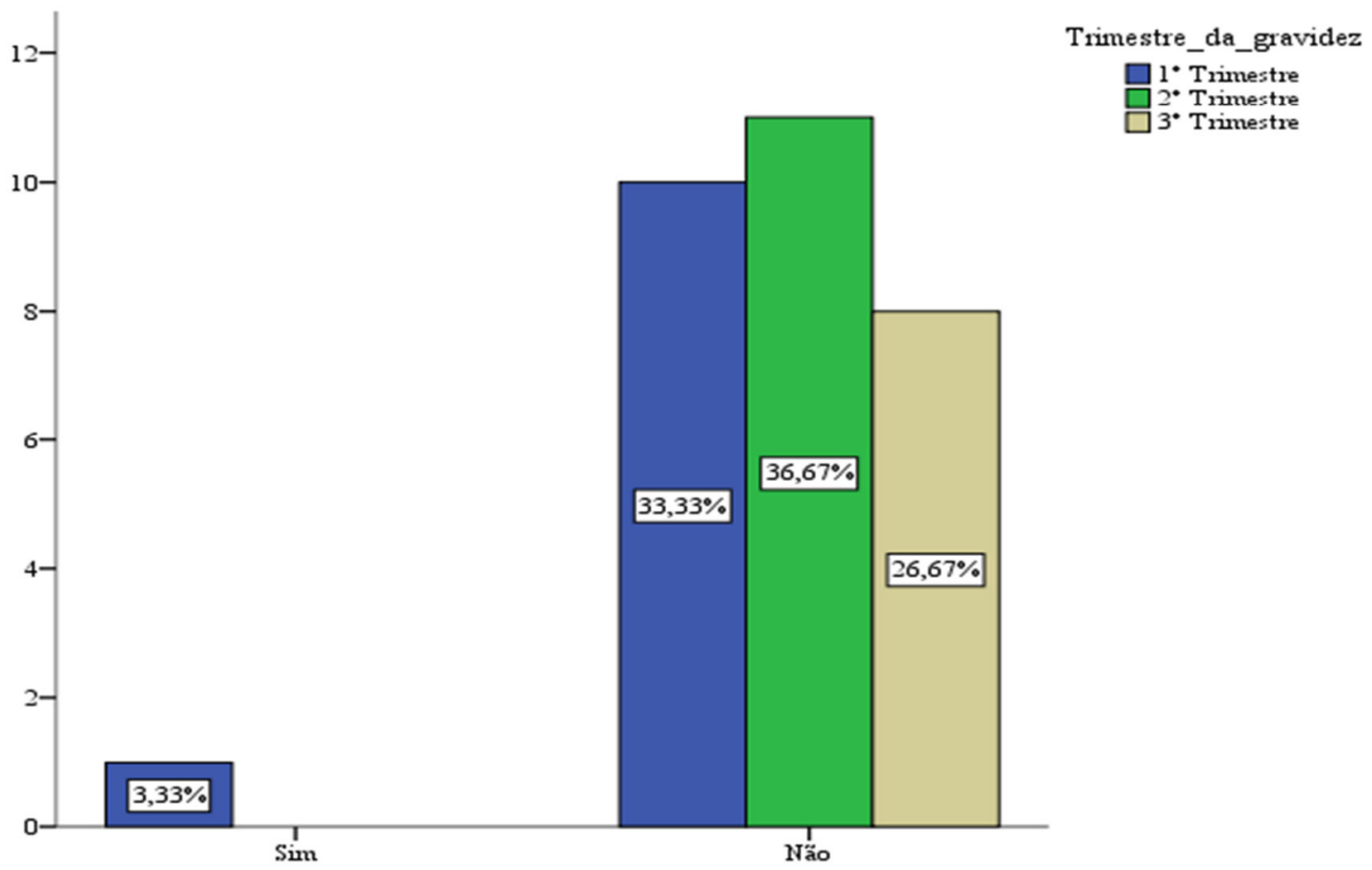

Fonte: Autoras, 2016.

Em um estudo realizado por Gubert (2015), foram avaliados 329 protocolos de gestantes que realizaram urocultura, sendo que destas, 149 estavam no primeiro trimestre de gestação, e houve a maior positividade para urocultura, totalizando 21 culturas positivas. Esse fator evidencia que as infecções do trato urinário possuem maior índice de ocorrência no primeiro trimestre gestacional, evento este que se torna muito preocupante, pois está relacionado ao parto prematuro, baixo peso, retardo mental e outros fatores, quando não tratada de forma correta.

Em relação às características clínicas das gestantes, a maioria $(74,07 \%)$ apresentou sinais e sintomas como corrimento, antes e durante a gestação, como também desconforto ou prurido no momento da micção, como mostrado no gráfico 2. 
Gráfico 2 - Prevalência de gestantes que apresentaram algum corrimento ou desconforto antes ou durante a gravidez na cidade de Cajazeiras - PB.

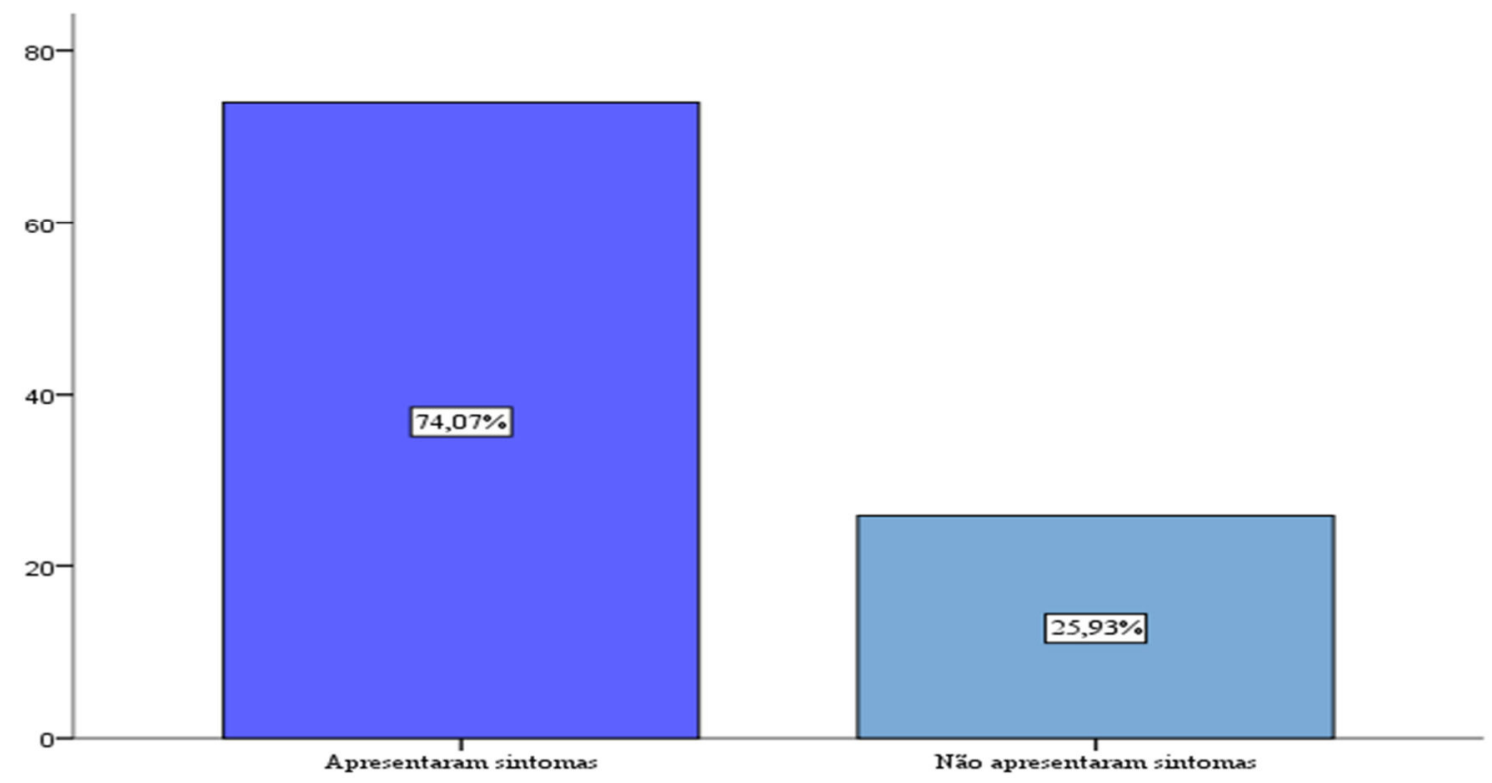

Fonte: Autoras, 2016.

O estudo realizado por Guerra e colaboradores (2012) em Recife - PE concorda com os resultados apresentados no gráfico 2, afirmando que analisar sinais e sintomas de infecção do trato urinário (ITU) durante a gestação é um processo bastante complexo, pois muitos deles são habitualmente referidos pelas gestantes, não caracterizando ITU, mas sim são atribuídos devido às mudanças fisiológicas provocados pela gestação. Um estudo observou que, das 232 gestantes avaliadas, 46,5\%, relataram sintomas urinários, porém apenas 10 (4,3\%) apresentaram crescimento bacteriano na cultura de urina.

Os resultados das análises microbiológicas das 30 amostras coletadas revelaram a presença de apenas um microrganismo em uma única amostra, sendo ela a Escherichia coli. A Escherichia coli refere-se a até $50 \%$ das infecções nosocomiais e de $70 \%$ a $90 \%$ das infecções do trato urinário, dos quais $90 \%$ atingem mulheres jovens e $20 \%$ já adultas, o que condiz com o trabalho de Korb e colaboradores (2013), realizado no município de Fazenda Rio Grande, Região Metropolitana de Curitiba, que avaliou, a partir de 265 antibiogramas, pacientes 
ambulatoriais portadores de infecções do trato urinário, dos quais 240 (90,5\%) foram positivos para Escherichia coli.

A Escherichia coli é o agente causal de $80 \%$ dos casos de proliferação de agentes infecciosos durante a gestação e por esse motivo é considerado o uropatógeno mais comum de infecções urinárias em gestantes. É constituinte da flora normal do intestino humano, no entanto, também pode contaminar e ocasionar infecções extraintestinais, a exemplo de septicemias e infecções do trato urinário (PIGOSSO; SILVA; PEDER, 2016).

Com relação à realização do pré-natal, o gráfico 3 mostra que a maioria das gestantes $(93,33 \%)$ realizam o pré-natal nas datas previstas, o que favorece a minimização de riscos durante o período da gestação, sendo positivo ao estudo de Corrêa e colaboradores (2014). O suporte ao pré-natal (PN) auxilia no controle e constatação de variadas doenças, fatores de risco e tratamento para inúmeras patologias, referente à saúde da gestante e do feto, a partir de um estudo realizado em São Paulo com dados de registros de 308 gestantes em uma unidade de Estratégia de Saúde da Família, em que se observou o início precoce do PN $(82,1 \%)$ e realização do mínimo de seis consultas (84,1\%) (CORRÊA et al., 2014).

Gráfico 3 - Gestantes que realizaram o pré-natal na Cidade de Cajazeiras - PB.

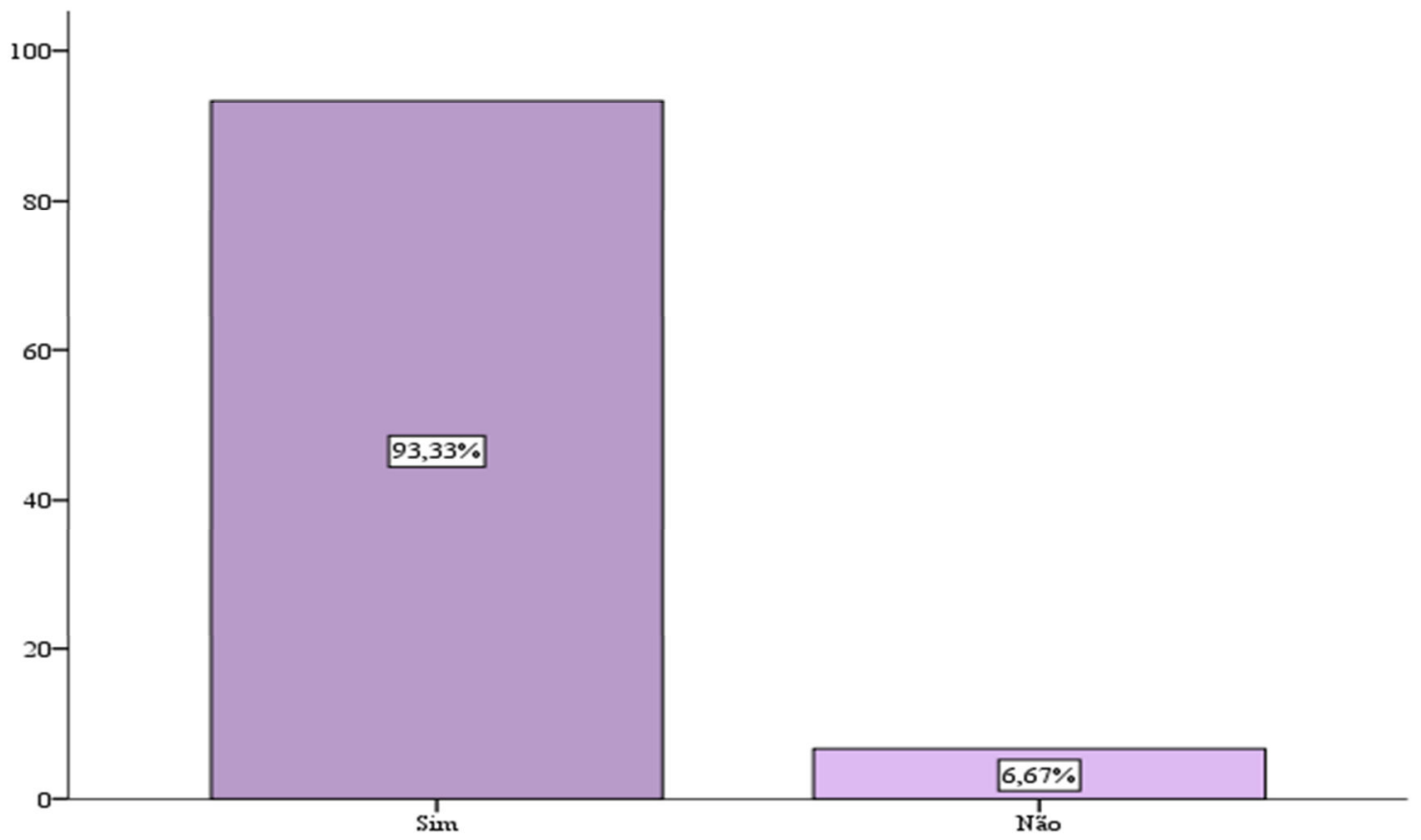

Fonte: Autoras, 2016. 
Quanto ao tratamento, os AINEs (Anti-inflamatórios Não Esteroides) são uma classe de fármacos que possuem atividade anti-inflamatória, além de ações analgésica, antitérmica e antitrombótica. No entanto, para tratamento de infecção urinária em gestantes não são recomendados, o que restringe e dificulta a escolha do fármaco na conduta médica. Em casos mais extremos e de necessidade de uso obrigatória, sua utilização deve ser suspensa antes do parto, para que se evitem complicações, como por exemplo tempo de parto prolongado e aumento de hemorragia pós-parto (PINHEIRO, R. M.; WANNMACHER, L; 2012).

Quanto à utilização de antibióticos, a maioria apresenta resultados satisftorios no combate a infecção do trato urinário, sendo normalmente eliminados pelo rim. No entanto, alguns antibióticos podem apresentar toxicidade ao feto, o que faz com que não sejam recomendados diminuindo o arsenal terapêutico (SILVA; SOUSA; VITORINO, 2019).

Assim, podemos observar, no gráfico 4 , que, das $74,07 \%$ das gestantes que apresentaram sinais e sintomas, apenas $40,74 \%$ foram orientadas a realizar tratamento à base das referidas substâncias. 
Gráfico 4 - Prevalência de gestantes que realizaram antibioticoterapia na gravidez na cidade de Cajazeiras - PB.

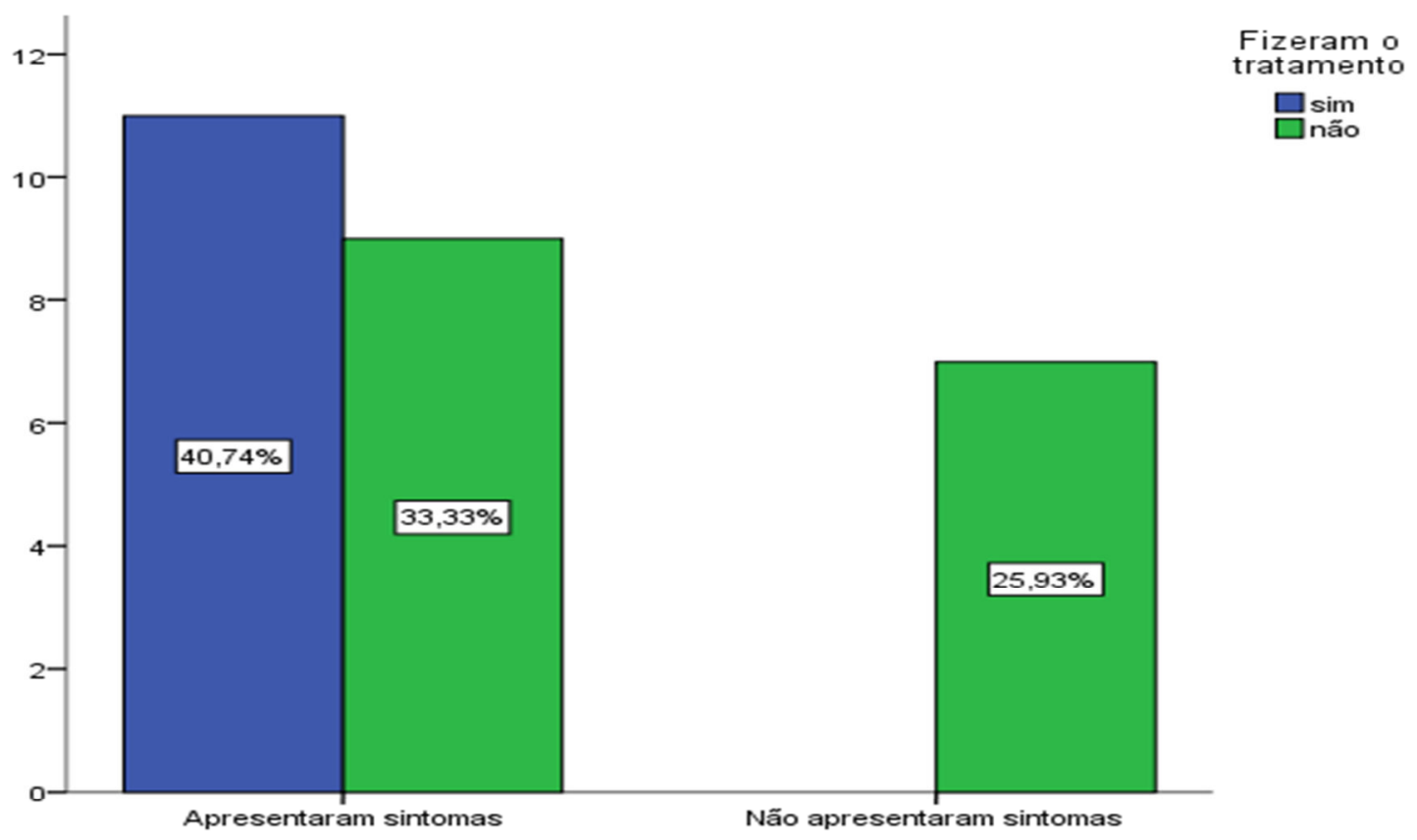

Fonte: Autoras, 2016.

Assim, podemos perceber a grande relevância da realização dos exames do pré-natal e antibiograma, com o intuito de assegurar um diagnóstico precoce de uma possível ITU na gestante, discernindo seu agente causador para traçar o perfil de sensibilidade antimicrobiana deste, com o uso de antibiótico pertinente, a fim de obter um tratamento eficaz e seguro (YANASE, 2018).

\section{CONCLUSÃO}

O presente estudo foi de encontro à maior parte do que a literatura utilizada para desenvolvimento da pesquisa evidenciou, mostrando o crescimento bacteriano na grande maioria das amostras com as uroculturas realizadas em gestantes em diferentes trimestres gestacionais, uma vez que o estudo realizado apresentou 
crescimento bacteriano em apenas uma amostra. Vale ressaltar que, das 30 amostras, 5 apresentaram crescimento bacteriano. No entanto, este crescimento foi inferior a 105 UFC, o que descaracteriza uma infecção urinária, pois as mudanças fisiológicas que ocorrem no período da gestação favorecem para um quadro sintomático de proliferação bacteriana no trato urinário.

Pelo fato de ser comum em gestantes, a pesquisa objetivou investigar a presença de infecções do trato urinário em gestantes da cidade de Cajazeiras - PB cadastradas nas principais Unidades Básicas de Saúde, a partir de amostras de urina testadas laboratorialmente, através do EAS e urocultura, afim de identificar tanto a presença da bacteriúria (através do EAS) como a espécie bacteriana causadora da infecção (através da urocultura).

Os resultados encontrados no presente estudo revelam que, apesar da literatura afirmar a grande prevalência de ITU em gestantes, a pesquisa releva-nos o antagônico, com apenas uma amostra positiva. Tal fato, portanto, pode ser justificado pela possibilidade de interferentes no processo de coleta e transporte dessas amostras, o que pode ter gerado resultados falsos negativos que não foram contabilizados.

\section{REFERÊNCIAS BIBLIOGRÁFICAS}

ALVES, D. M. S.; EDELWEISS, M. K.; BOTELHO, L. J. Infecções comunitárias do trato urinário: prevalência e susceptibilidade aos antimicrobianos na cidade de Florianópolis. Revista Brasileira de Medicina de Família e Comunidade, [s.I.], v. 11, n. 38, p. 1-12, 19 set. 2016.

BRASIL. Ministério da Saúde. Secretaria de Atenção à Saúde. Departamento de Ações Programáticas Estratégicas. Gestação de alto risco: manual técnico / Ministério da Saúde, Secretaria de Atenção à Saúde, Departamento de Ações Programáticas Estratégicas. - 5. ed. Brasília: Editora do Ministério da Saúde, 2012. 302 p. - (Série A. Normas e Manuais Técnicos).

CORREAA M. D.; TSUNECHIRO M. A.; LIMA M.O. P.; BONADIO I. C. Avaliação da assistência pré-natal em unidade com estratégia saúde da família. Revista eletrônica da Escola de Enfermagem da USP. 2014, vol.48, pag. 24-32.

FERNANDES F. A.; OLIVEIRA C. N. T.; SOUZA C. L.; OLIVEIRA M. V. Relevância do diagnóstico e tratamento da infecção do trato urinário em gestantes: uma revisão da literatura. C\&D-Revista Eletrônica da Fainor, Vitória da Conquista, v.8, n.1, p.54-70, Jan./Jun. 2015.

FREITAS, B. V. L.; GERMINO, R. V.; TRINO, L. M.; DIÓRIO, S. M.; FUSARO, A. E. Prevalência e perfil de susceptibilidade a antimicrobianos de uropatógenos em pacientes atendidos no Instituto Lauro de Souza Lima, Bauru, SP. Revista Brasileira de Análises Clínicas, [s.I.], v. 48, 
n. 4 , p. $375-380,2016$.

GOMES, I.; METELLO, J.; FREITAS, B.; DIOGO, J. Infeções urinárias na gravidez. Acta Obstet Ginecol Port, Coimbra, v. 11, n. 4, p. 248-254, out. 2017. Disponível em $<$ http://www.scielo.mec.pt/scielo.php?script=sci_arttext\&pid=S1646-

58302017000400004\&lng=pt\&nrm=iso>. Acesso em: 15/04/2020.

GUBERT J. C.; MATTOS A. S.; SOUSA P. G.; COLACITE J. Infecção urinária em gestantes: avaliação dos casos atendidos por um laboratório do oeste do paraná no ano de 2013. Revista Eletrônica Acta Biomedica Brasiliensia volume 6, $\mathrm{n}^{\circ}$. 1, julho de 2015. Disponível em: www.actabiomedica.com.br. Acesso em: 14/03/2016.

GUERRA G. V. Q. L.; SOUZA A. S. R.; COSTA B. F.; NASCIMENTO F. R. Q.; AMARAL M. A.; SERAFIM A. C. P. Exame simples de urina no diagnóstico de infecção urinária em gestantes de alto risco. Revista Brasileira Ginecologia Obstetrícia. 2012; 34, pag. 488-93.

KORB A.; NAZARENO E. R.; MENDONÇA F. A.; DALSENTER P. R. Perfil de resistência da bactéria Escherichia coli em infecções do Trato urinário em pacientes ambulatoriais. Revista eletrônica de biologia e ciências da terra, volume 13, $n^{0} 1$ - $1^{\circ}$ Semestre 2013.

KORKES F.; RAUEN E. C.; HEILBERG I. P. Litíase urinária e gestação Urolithiasis and pregnancy, Journal of Brazilian Nephrology 2014; 36, pag. 389-395.

LACERDA W. C.; VALE J. S.; LACERDA W. C.; CARDOSO J. L. M. S. Infecção urinária em mulheres: revisão da literatura. Revista eletrônica Saúde em Foco, ed. n: 07, ano. 2015.

MATA K. S.; SANTOS A. A. P.; SILVA J. M. O.; HOLANDA J. B. L.; SILVA F. C. L. Complicações causadas pela infecção do trato urinário na gestação. Revista espaço para a saúde, Londrina v. 15 n. 4 p. 57-63 out/dez. 2014.

ONOH R.C.; UMEORA O.U.J.; EGWUATU V.E.; EZEONU P.O.; ONOH T.J.P. Antibiotic sensitivity pattern of uropathogens from pregnant women with urinary tract infection in Abakaliki, Nigeria. Open access to scientific and medical research, Infection and Drug Resistance 2013, pag. 225-233, 29 Nov. 2013.

PAGNONCELI, J.; ABEGG, M. A.; COLACITE, J. Avaliação de infecção urinária em gestantes do município de Marechal Cândido Rondon - PR. Arq. Ciênc. Saúde Unipar, Umuarama, v. 14, n. 3, p. 211-216, set./dez. 2010.

PAULA V. T.; SILVA D. V.; MENDES E. M.; TRIGUEIRO T. H. A enfermagem na identificação da infecção urinária na gestação: uma revisão integrativa. $7^{\circ}$ conclave dos acadêmicos de enfermagem da universidade positivo (conaenf), Out/2015.

PIGosso, Y. G.; SILVA, C. M.; PEDER, L. D. Infecção do trato urinário em gestantes: incidência e perfil de suscetibilidade. Acta Biomedica Brasiliensia, vol. 07, $\mathrm{n}^{\circ} .01$, ano 2016 , pag. 64-73.

PINHEIRO, R. M.; WANNMACHER, L. Uso racional de anti-inflamatórios não esteroides. Ministério da Saúde. Uso Racional de Medicamentos Temas relacionados. Brasília: Editora MS, 2012. Cap. 5, p. 41-50.

SANTOS, L. S.; DAMASCENO, N. S.; SOUTO, R. C. F. Resistência de bactérias Grampositivas isoladas de infecção do trato urinário no LAC/PUC Goiás. Revista Brasileira de Análises Clínicas, [s.I.], v. 51, n. 2, p. 143-148, 2019.

SANTOS, C. C.; MADEIRA, H. S.; SILVA, C. M.; TEIXEIRA, J. J. V.; PEDER, L. D. Prevalência de infecções urinárias e do trato genital em gestantes atendidas em Unidades Básicas de Saúde. Revista de Ciências Médicas, [s.I.], v. 27, n. 3, p. 101-113, 2018. 
SILVA, R. A.; SOUSA, T. A.; VITORINO, K. A. Infecção do trato urinário na gestação: diagnóstico e tratamento. Revista Científica Faema, [s.I.], v. 10, n. 1, p. 71-80, 26 jul. 2019.

VERAS, D.; SOUSA, K. M. O.; RODRIGUES, E. S. R. C.; NÓBREGA, M. M. Incidência de gestantes com infecção do trato urinário e análise da assistência de saúde recebida na UBS. Temas em Saúde, Joao Pessoa, v. 16, n. 4, ano 2016, p. 48-62.

YANASE, L. E. Padrão da microbiota em uroculturas das gestantes do hospital Santo Antônio de Blumenau e os padrões de sensibilidade aos antimicrobianos. Arquivos Catarinenses de Medicina, [S.I.], v. 47, n. 4, p. 73-79, dez. 2018. Disponível em: <http://www.acm.org.br/acm/seer/index.php/arquivos/article/view/399/307>. Acesso em: 15 abr. 2020. 